\title{
The Semantics of Conspicuity: Design Strategies to Address Conspicuity in Type 1 Diabetes Medical Devices for Adolescents
}

\begin{abstract}
This paper reports on the development of semantic strategies designers can use when designing medical devices for adolescents with type 1 diabetes to match their preferences for conspicuity. Adolescents with type 1 diabetes use medical devices that can cause unwanted attention in public settings and can create perceived social pressures. The semantic strategies address conspicuity by enhancing the traditional medical device to make it more beautiful, disguising the medical device as a non-medical item, concealing the medical device from the public, personalising the medical device for the user, and using technology to advance the medical device. Participatory design methods were used to understand adolescents' experiences of using medical devices in public and how the semantic strategies could be applied to match their preferences for conspicuous or inconspicuous medical devices. Both adolescent participants with type 1 diabetes felt comfortable testing in public; there were occasions where they did not want to answer questions from onlookers. Participants favoured a combination of the semantic strategies. In particular, they were making the device look less "medical" and more beautiful, and utilising technology to make the device more inconspicuous. This research developed semantic strategies to design new medical devices that match adolescent preferences for conspicuity.
\end{abstract}

\section{Keywords}

Type 1 Diabetes, Conspicuity, Semantics, Participatory Design, Adolescents

\section{Introduction}

Type 1 diabetes is an invisible, chronic autoimmune disease where the pancreas is unable to produce insulin to regulate glucose levels in the body. Adolescents aged 13-18 with type 1 diabetes are required to follow an intensive self-management regimen that includes, frequent monitoring of blood glucose levels, diet, exercise and self-administering insulin [1]. Adolescent development research shows that selfmanaging in public spaces can be challenging, as it can draw unwanted attention and questions, at a life stage when social acceptance is critical [1]-[3], this is commonly referred to as stigma. The term stigma did not accurately represent adolescent experiences, as it is a word that elicits strong emotions that not all adolescents feel towards their medical devices [2]. Whereas the term conspicuity does, as adolescents do not always want to be the centre of attention and would prefer an inconspicuous device in specific settings.

Previously the priorities when designing for medical conditions and disabilities have been to enable the user while attracting as little attention as possible [4]. This traditional approach has been less about creating a positive image around a medical condition, and more about designing an object which projects no image at all.

Semantics should be considered while designing medical devices [5] for adolescents with type 1 diabetes. Krippendorf and Butter [6] have defined product semantics as: "the study of symbolic qualities of man-made forms in the context of their use and the application of this knowledge to industrial design." 
Product semantics requires the designer to understand the context in which the product is used and addresses how the product communicates in its environment [6]. Semantics has been used in past research to describe strategies to elicit surprise through the design of a product [7], similar semantic strategies have been developed in this research; however, the strategies aim to design conspicuous or inconspicuous medical devices.

Adolescents' self-management of type 1 diabetes should be considered in a social context, and the semantics of the medical device should be reflected when designing for adolescents with type 1 diabetes. In this research, we aim to develop strategies that address the semantics of conspicuity to enable designers to create medical devices that provide adolescents with the opportunity to disclose their medical condition when they choose.

\section{Methods}

\subsection{Development of Semantic Strategies}

The strategies were developed by analysing literature through thematic analysis [8]. We used the six-phase approach to thematic analysis [8]. The thematic analysis comprised stages of familiarising yourself with the data, generating initial codes, searching for themes, reviewing potential themes, defining and naming themes and producing a report. The literature analysed included five different pieces that discuss strategies to reduce product-based stigma (being the more common terminology than conspicuity). The strategies in the literature were disregarded if they did not address the design of a tangible product. Table 1 describes the final themed strategies.

\subsection{Participatory Design}

Participants were two adolescents with type 1 diabetes aged 15. One boy and one girl took part in the semistructured interviews, collage, and sketching. The two participants were involved in the initial development and exploration of the strategies. Participatory design methods were used in the research so that adolescents with type 1 diabetes were able to discuss the semantic strategies and share their opinions and experiences. Participation in design involves open dialogue, communication and trust [9]. Participatory design is a process of investigating, understanding, reflecting, establishing and developing ideas with participants [10].

The participants took part in semi-structured interviews, collaging and sketching activities to discuss their preferences towards conspicuity and to visualise their preferred semantic strategies. A collage is a less formal and more creative way to discuss ideas. It provides adolescents with an opportunity to project personal information onto visual artefacts [11]. The images used for the collage are of products that could be categorised into one of the developed semantic strategies.

Sketching with the adolescents' allowed the participants to sketch their ideal future concepts. The sketch concepts were influenced by the collage and the ideas discussed in the interviews. This is an opportunity for the adolescents to tailor the concepts towards type 1 diabetes medical devices and sketch new more conspicuous or inconspicuous devices based on their preferences. Thematic analysis was also used to analyse the interviews collages, and sketches. Themes from the interviews were identified and compared with the developed semantic strategies.

\section{Results}

The final results discussed in this section includes the five semantic strategies, the results from the interviews discussing the strategies, or experiences relating to the strategies and the participant sketches of possible medical devices.

\subsection{Semantic Strategies that Address the Conspicuity of Medical Devices}

The final semantic strategies developed through thematic analysis, range on a scale (fig. 1) from conspicuous to inconspicuous to allow for adolescents' preferences to be met. Strategy 5 and 4 could be both be designed as inconspicuous or conspicuous objects, therefore their points extend across the scale. Each strategy also provides a different level of consumer appeal and medical appeal, which can also be demonstrated in figure 1 . The majority of current medical devices (fig. 5) would lie within the medical and conspicuous area of the diagram. The final strategies are outlined below. 


\section{Enhance the Aesthetic Appearance of the} Traditional Medical Device. The advantages of enhancing the aesthetics of a medical device are that it allows the device to appear less "medical." By enhancing the aesthetics, it can make the device more innovative, stylish and modern. This can be achieved through colour, texture, pattern, material or form. An example of enhancing the aesthetic appearance of the traditional medical device is Epipi designed by Harry Moorman (fig. 2). Epipi still retains some of the traditional elements of an EpiPen; however, it has been improved through choices such as material, colour, and texture.

\section{Personalise the Medical Device for the User.}

By personalising an object, it provides the user with a sense of ownership over the object. Personalisation
Table. 1. Strategies developed through thematic analysis

\begin{tabular}{|c|c|c|c|}
\hline Theme & Source & Strategy & Description of strategy \\
\hline \multirow{4}{*}{$\begin{array}{l}\text { Enhance the } \\
\text { traditional } \\
\text { a medical device to } \\
\text { make it more beautiful }\end{array}$} & [12] & Fading out and Disguising & $\begin{array}{l}\text { Hide and replace unpleasant features, with more pleasant ones, } \\
\text { which fit the context. }\end{array}$ \\
\hline & [12] & Drawing Positive Attention & $\begin{array}{l}\text { Design devices that create positive attention for assistive } \\
\text { technologies }\end{array}$ \\
\hline & [3] & $\begin{array}{l}\text { Reinforce the medical role } \\
\text { played by the device }\end{array}$ & $\begin{array}{l}\text { Design the device with materials, colours and textures that make } \\
\text { it appear medical. }\end{array}$ \\
\hline & [13] & Diversion of attention & $\begin{array}{l}\text { Create a diversion of attention away from the medical aspects of } \\
\text { the device. }\end{array}$ \\
\hline \multirow{4}{*}{$\begin{array}{l}\text { Disguise the medical } \\
\text { device as a non- } \\
\text { medical item }\end{array}$} & [13] & Camouflage - disguise & Camouflage or hide the medical aspects. \\
\hline & {$[13]$} & Extra ability & The device provides another ability. \\
\hline & [13] & $\begin{array}{l}\text { Reshaping product meaning } \\
\text { through meaningful interaction } \\
\text { with other products }\end{array}$ & $\begin{array}{l}\text { The interaction of products can be cooperative, competitive, or } \\
\text { independent. }\end{array}$ \\
\hline & {$[3]$} & $\begin{array}{l}\text { Downplay stigma sensitive } \\
\text { features by disguising the } \\
\text { product as an accepted non- } \\
\text { medical item }\end{array}$ & $\begin{array}{l}\text { Make the device less noticeable and allow the user to hide their } \\
\text { type } 1 \text { diabetes. }\end{array}$ \\
\hline \multirow{3}{*}{$\begin{array}{l}\text { Conceal the medical } \\
\text { device from the public }\end{array}$} & [14] & Covering the stigmatising object & Conceal the disabling or stigmatising part of the product \\
\hline & {$[3]$} & $\begin{array}{l}\text { Minimise stigma-sensitive } \\
\text { aspects of the device by making } \\
\text { it invisible or less confronting } \\
\text { and minimise its presence. }\end{array}$ & Make the device less noticeable and less embarrassing in public \\
\hline & {$[12]$} & Hiding and Covering & Hiding to manage both visible and non-visible stigma. \\
\hline \multirow{3}{*}{$\begin{array}{l}\text { Personalise the } \\
\text { medical device for } \\
\text { the user }\end{array}$} & [12] & Personalisation & Products feel more tailored to the user \\
\hline & {$[11]$} & Individual identity & $\begin{array}{l}\text { Allow the user to personalise their device, either through mass } \\
\text { customisation, or the user incorporates their own identity. }\end{array}$ \\
\hline & [3] & $\begin{array}{l}\text { Strengthen the individual } \\
\text { identity of the device by } \\
\text { providing more opportunities } \\
\text { for personalisation, so users } \\
\text { value it as an extension of their } \\
\text { personality. } \\
\end{array}$ & $\begin{array}{l}\text { Provides participants with a sense of control and ownership over } \\
\text { their device. It reflects the user's style and allows them to feel } \\
\text { proud of their device. }\end{array}$ \\
\hline \multirow{2}{*}{$\begin{array}{l}\text { Use } \\
\text { technology to advance } \\
\text { the medical device }\end{array}$} & {$[12]$} & Designing Stigma Out & $\begin{array}{l}\text { Technology can be used for reshaping the user. Assistive products } \\
\text { can become more varied, tailored and personalised. }\end{array}$ \\
\hline & {$[11]$} & $\begin{array}{l}\text { Reshaping product meaning } \\
\text { through advances in material } \\
\text { technology }\end{array}$ & $\begin{array}{l}\text { By integrating new technology into an existing product, it provides } \\
\text { the designer with a way to reshape a product }\end{array}$ \\
\hline
\end{tabular}



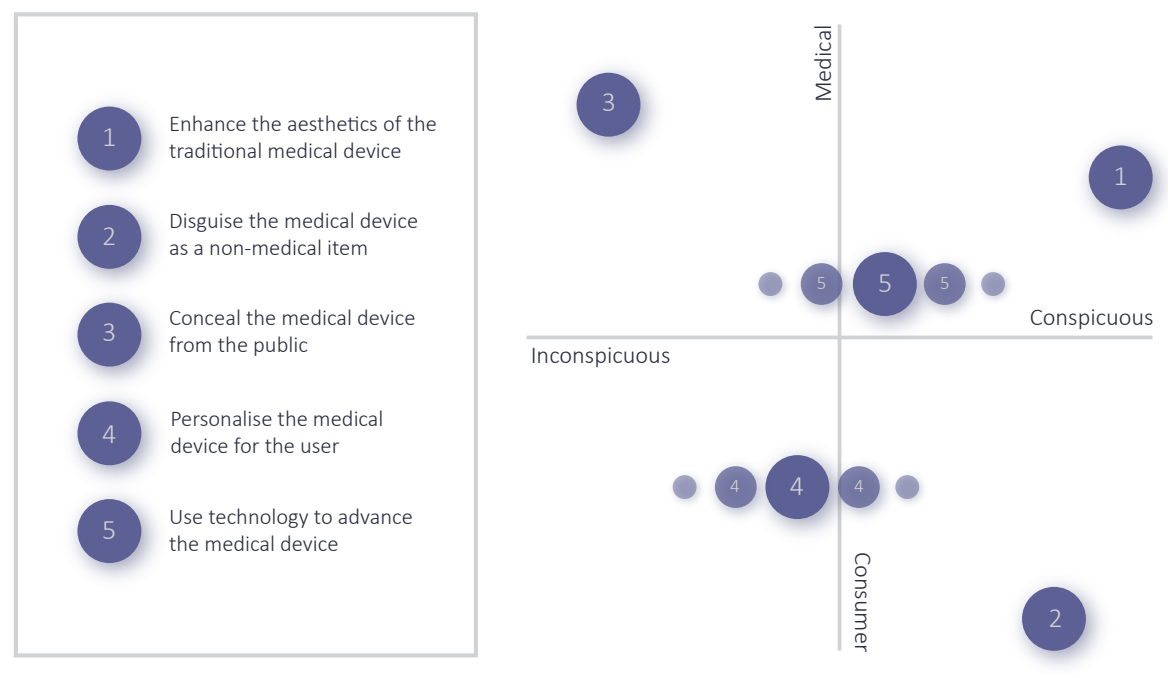

Fig. 1. Diagram showing the conspicuousness and consumer appeal of the strategy can be achieved through providing the user colour options, patterns and engraving. Jacobsen [12], Vaes [13] and McCarthy [3] all mentioned this strategy in their research as a way of making the user proud of the object and therefore encouraging them to use their devices more regularly.

The Hue inhaler (fig. 3) designed by Tim Zarki is a device that demonstrates the opportunity for personalisation. The Hue inhaler is a device that not only fits into the personalisation strategy but also could be an example of enhancing the aesthetic appearance of the traditional medical device. Personalisation is a strategy that aligns well with several other strategies, as it can be achieved through small changes, and provides the user ownership over their medical devices.

\section{Disguise as an Accepted Non-Medical Device.}

This strategy aims to remove the 'medical' aspects from the design to create a conspicuous object that can be used openly in public spaces. Disguising the medical device as another object allows adolescents to use the product in public, without the object being recognised as a type 1 diabetes medical device. This strategy is similar to, two of Vaes's [13] strategies that aim to reduce stigma in products. The strategies aimed to camouflage or disguise the products. McCarthy [3] also used this strategy; however, renamed it as "disguise the product as an accepted non-medical item." Examples of this strategy could include disguising medical devices in everyday objects such as a watch, cell phone, or keys.
Conceal the Medical Device from the Public. For adolescents who are more embarrassed by their type 1 diabetes or their medical devices, they might gravitate towards concealing their medical device from the public. This strategy is different from disguising as an accepted non-medical device, as it asks the designer to remove the object from the view of the public altogether. This strategy often works well with technological advancement, as many of the opportunities to design for this strategy are through wearable technologies such as temporary tattoos (fig. 4), contact lenses, and microchips. This strategy is a useful one to consider as it withdraws the device from the view of the public, making it more comfortable for adolescents to test in public discreetly if they choose to.

\section{Technological Advancements. As technology} advances, the desire for newer, smaller and slimmer type 1 diabetes medical devices is becoming apparent
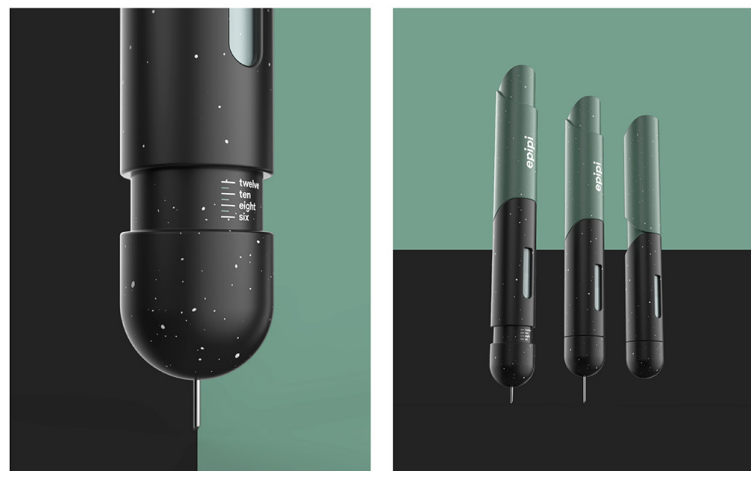

Fig. 2. Epipi. Image courtesy of Harry Moorman. 
Fig. 3. Hue Inhaler. Image courtesy of Tim Zarki.

Fig. 5. Current traditional type 1 diabetes medical devices available in New Zealand
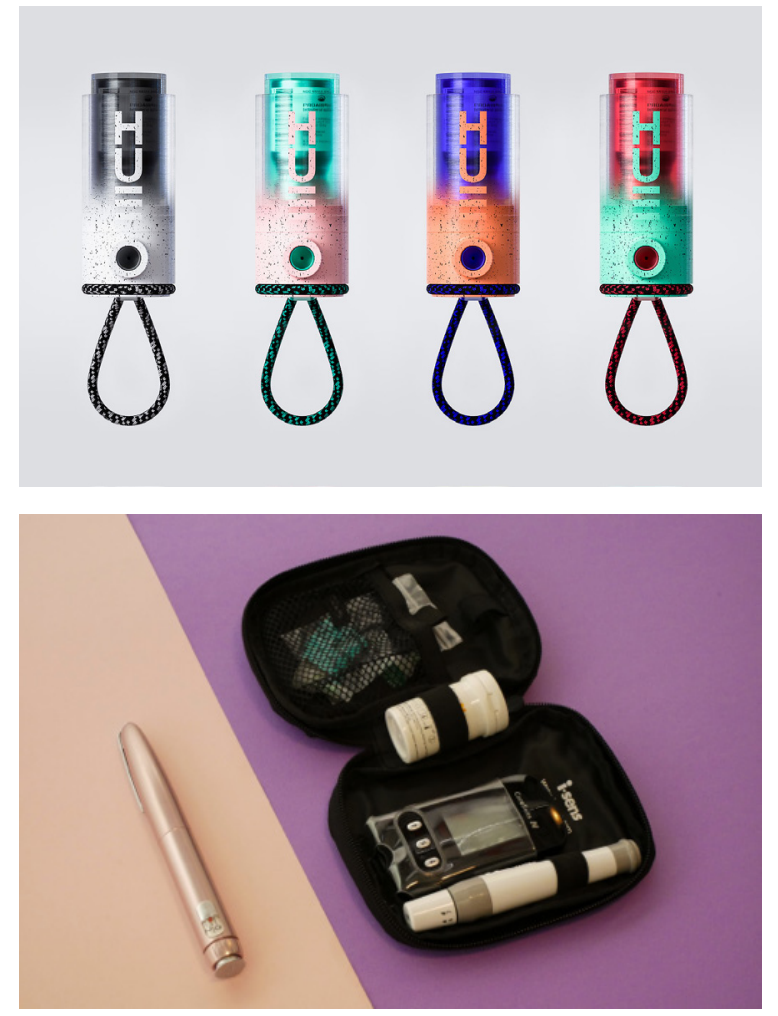

[15]. Developments in technology have allowed for more experimental blood-glucose meters such as the Freestyle Libre, the tattoo blood glucose sensor, the Google lens blood glucose meter, and blood-glucose ink. As technology develops, it will become increasingly more accessible for us to visualise the possibilities for new, more inconspicuous medical devices.

\subsection{Conspicuity of Testing in Public}

In the interviews, both participants were not concerned about testing in public; participant 2 responded: "I don't mind testing in public, because I feel like it's something you need to do." It is important to respect the adolescents' experiences; however, there is a nuance to attention. Some adolescents might not feel embarrassed but do not want to be forced to disclose their type 1 diabetes or made to answer questions at that moment. We recognise that there is a variety of opinions, and the preferences of other adolescents' that have not been interviewed should be considered.

The adolescents interviewed were also aware of this; participant 1 had been diagnosed at a young age but was aware that someone who had been recently diagnosed might have different opinions about testing in public. "I've had it for 11 years, but if someone had it for three months or something, it might become more awkward for them, and they might want to go off and do it privately." Therefore, it is essential to consider the occasions when the participants do not want to be asked questions about their medical devices or type 1 diabetes, as they might be busy, not in the mood or embarrassed.

One of participant 1's first thoughts about creating a conspicuous device was: "I think the whole thing of this is trying to make sure people do not look at it and immediately think 'oh it's medical, what's wrong?'” Participant 2 was less concerned about the device being medical and more interested in making the device "innovative and stylish." Current devices (fig. 5) available in New Zealand use colours, materials, shapes and interfaces that make the device appear traditionally 'medical'.

Type 1 diabetes devices are frequently a blue colour, as participant 2 explained: "Well you know how there is a blue theme going through it, because it's clean, but it doesn't need to be because people don't want all blue." Participant 1 also mentioned that "there is like six colours for the pump, but it's very basic navy blue, green, black and grey." Although participants are not concerned about testing in public, they still desire a device that provides them with the autonomy to disclose their type 1 diabetes when they chose. A combination of the semantic strategies would provide them with a device that matches their preferences for conspicuity.

\subsection{Preferences for Semantic Strategies}

The participants did not gravitate towards a specific strategy in their interview, collage or sketches. Both participants preferred a combination of strategies. Two of the themes generated from the interviews involved technology and aesthetics; these were the preferred strategies from the participants combined with aspects from other strategies. Several ideas were discussed that generated ideas which combined aspects of the strategies.

\section{Preferences for Strategies as Discussed}

in Interviews. Participant 1 was interested in exploring the possibilities of either making the device inconspicuous and not seen by the public or 
conspicuous and onlookers know what the device is. Participant 1 believed when a medical device is conspicuous and appears medical such as a wheelchair, crutches or even a tracheostomy; onlookers typically do not ask questions as they are aware of what the item is. Questions are also not asked when the onlooker cannot see an item at all. People will begin to ask questions when they are unsure if the object is medical or not.

P1: I think the main thing is that there is something where it's so obvious it's not medical- where people don't ask about it. Then there is a period where it shows that it's medical, so people don't ask about it, and then there's that middle zone, where people are unsure whether it's medical or not, so people ask you about it. But if you make it really discreet or really obvious people won't ask you about it.

One of the ideas Participant 1 discussed to demonstrate this, was to make a conspicuous phone case disguised as a blood-glucose meter:

P1: Putting a sensor on your phone, but you can also use it to see your readings, so you would unlock your phone and see the readings, have something that is made for one use, like this one the fingerprint detector, making it able to be used for another thing.

This concept would allow the adolescent to use the medical device in public in a very conspicuous way. Combining the medical device with an object that used daily such as a cell phone, would also be more convenient.

Both participants were interested in how technology could make their blood glucose meters smaller or concealed. They both thought of ideas that would allow for a blood-glucose sensor to be implanted into their veins. Participant 2 thought of an idea similar to a bracelet: "What if it was like a bracelet and the bracelet was in your vein? I don't know that would be painful though" and participant 1 had already seen tools that could be powered by blood and was intrigued by that prospect: "There are tools where it can be powered by blood, so if the sensor was a microchip it would be selfsustainable." These ideas show how the participants are interested in exploring the possibilities of technology creating smaller and more inconspicuous devices.

Both participants placed the images of the Hue inhaler (fig. 3) and Epipen (fig. 2) on their collage, as they both liked the colour options and that it did not immediately appear 'medical'. Participant 1 said that the Hue device offers personalisation "A lot of these are quite subtle. I think this one with all the colours, it doesn't make it look like its medical. It provides that personalisation." Participant 1 also said "The EpiPen, that model will be good for an insulin pen. You look at it, and you don't think anything medical, it looks cool. It gives a different vibe." Both of these images show how personalisation and enhancing aesthetic appearance are strategies that could be explored in the future design process.

\section{Adolescent Preferences for New Concepts} as Shown through Sketches. Both participants sketched the idea of an "all-in-one" device. They both found their current systems inconvenient, and participant 2 regarded carrying everything with them as annoying, "obviously there is not a time when you wouldn't need your insulin pen." Convenience is a theme that was mentioned repeatedly by both participants. Participant 2's "all-in-one" device (fig. 6) is a portable testing and administering device. "You could have a three in one tool! So, it would be like your injection, finger pricker and blood glucose meter." This device would not only be convenient but also a more beautiful device that would not be recognised as easily by the public due to the casing surrounding the device.

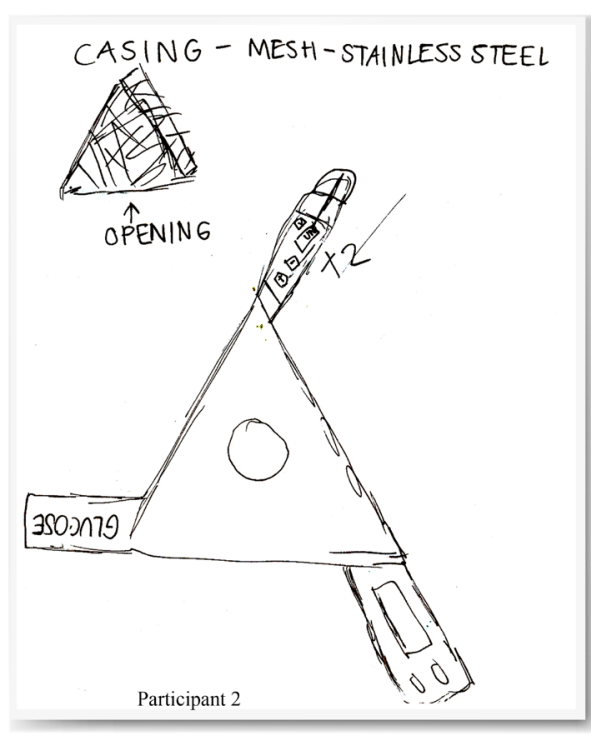

Fig. 6. Participant 2 all-in-one sketch;

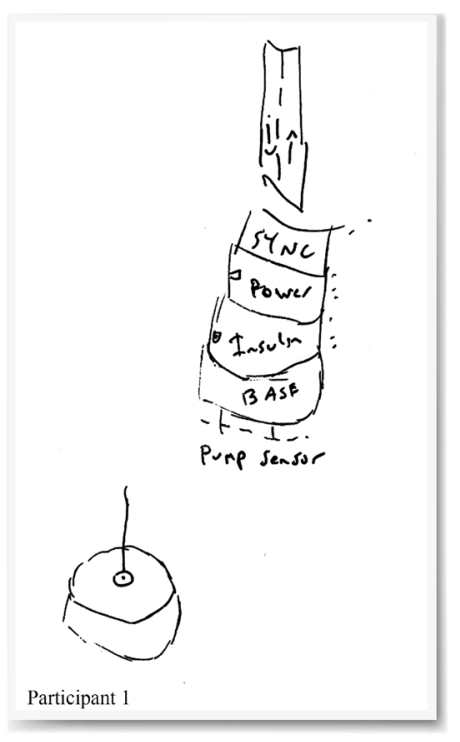

Fig. 7. [above right] Participant 1 modular sketch 


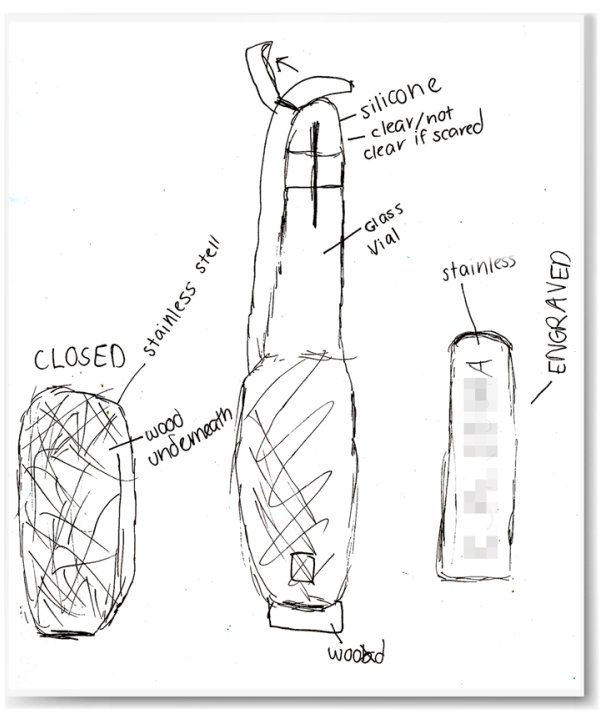

Fig. 8. First concept drawn with participant 2

Like participant 2, participant 1 wanted a convenient device and linked all his current devices together. They wanted the opportunity to create an all-in-one modular continuous blood glucose meter (fig. 7). The modular device would be worn on the arm, like the freestyle Libre. Participant 1: "Yeah, you could have lots of pieces! Ones got the insulin, ones got the battery, and ones got the Libre." The participant liked the idea of technology developing far enough in the future where all their devices could be in one spot on the body and all linked to a phone app to control blood glucose levels, and insulin administration. This device combined two strategies: technological advancements and concealed the medical device from the public to create a more inconspicuous and convenient device.

Participant 2 wanted to sketch a device that could be more "more innovative and stylish." The participant was interested in materiality, texture, patterns and colours to create a more beautiful device. In the sketch (fig. 8), the participant wanted to engrave their name onto the insulin pen design. Naming the device demonstrates a sense of ownership over the concept and shows that they are proud of the idea they have generated. The participant even said they were proud of the work: "Wow, I've never done art, but I am kind of proud of this." The device they have designed could fit into the personalisation category but also the "enhance the aesthetic appearance of the traditional medical device" as a metal mesh encases it. The device could also fit into the strategy "disguise as an accepted non-medical device."

\section{Discussion.}

The participants were comfortable testing their blood-glucose levels and administering insulin in public. However, they both had experienced questioning from curious people at school and sports practices regarding their medical devices. The participants both saw these questions as harmless. However, there are occasions where participants are not in the mood to be asked questions.

Adolescents had different preferences towards the five strategies developed and explored in this paper. Participant 1 was interested in technology, and how it could be used to make a more inconspicuous and convenient medical device and system. This was evident in the current devices the participant uses, which include a Freestyle Libre, insulin pump, MiaoMiao sensor and a smartwatch to receive constant readings. The participant did not want a device that appeared immediately "medical", and their preference towards inconspicuousness included wearing the device underneath clothing such as the Freestyle Libre. The semantics of using technology would allow their device to become smaller and more inconspicuous.

Participant 2 had a different preference for their chosen strategy. They preferred a conspicuous device that is more "innovative and stylish." They were drawn to colours, patterns, textures and materials. This was seen in their sketches (Figure 6 \& Figure 8), as they annotated specific materials and patterns that they would like to be seen in their concepts. Participant 2 was also interested in combining the personalisation strategy to allow for their device to be engraved with their name.

Both participants had similar opinions about conspicuity. However, they recognised that this is not representational of all adolescents with type 1 diabetes. Only two adolescents took part due to time constraints and access to participants. Although only two adolescents participated in this paper, the interviews were successful in understanding the participants' experiences of type 1 diabetes and provided a level of detail and story-telling that might not 
have been achieved through a questionnaire or survey. Participatory design methods also contributed to the detailed results. It allowed for the participants' opinions to contribute to the designing process, and the concept sketches are tailor-made to their needs.

The next step is to explore further how the strategies can be applied to type 1 diabetes medical devices. The participants interviewed in this paper found the questions and activities engaging and will be returning for future feedback sessions with higher-fidelity prototypes. Further research in this area would be interesting to see how designers could operationalise the strategies. Additionally, medical devices may not be the only area where a conspicuous product is preferred, other areas of design such as safety products, assistive products and wearable technology might be other areas to explore how the semantic strategies could address the conspicuity of products.

\section{Conclusion}

In this study, five semantic strategies that address the conspicuity of medical devices were developed and explored with adolescents who have type 1 diabetes. Thematic analysis of literature that explores stigma in product design was used to develop the strategies. The strategies are: enhancing the traditional medical device to make it more beautiful, disguising the medical device as a non-medical item, concealing the medical device from the public, personalising the medical device for the user, and using technology to advance the medical device. These strategies all aim to design conspicuous or inconspicuous medical devices for adolescents with type 1 diabetes.

Two participants took part in semi-structured interviews, collaging, and sketching to explore the five semantic strategies. The semi-structured interviews successfully created an open discussion around testing in public, conspicuity and their preferences for their medical devices. The participatory design methodology allowed for a detailed conversation and provided more context and insight on the topic in addition to the sketching of potential ideas.

Participants valued different strategies, in particular, using technology to advance the medical device and to enhance the traditional medical device to make it more beautiful. These strategies were often combined with aspects of other strategies to produce their ideal concept for a conspicuous or inconspicuous medical device. Continuing this research will require further exploration of the semantic strategies, to determine the best combination of strategies for future concepts of medical devices. Designers will also play an important role in the next phase of the research to understand if the strategies can be used in other design disciplines and by practising designers.

While the medical devices currently used by adolescents' do little to meet their preferences for conspicuity in public settings, this research has explored new strategies that could help to design new medical devices for adolescents with type 1 diabetes that can match their preferences for conspicuity.

Acknowledgements. This project was kindly sponsored by the Centre of Research Excellence in Medical Technologies (CoRE MedTech), New Zealand. We thank the two participants involved.

\section{References}

1. Borus, J.S. \& Laffel, L. (2010). Adherence challenges in the management of type 1 diabetes in adolescents: prevention and intervention, Curr. Opin. Pediatr., 22 (4), pp. 405-411.

2. Brazeau, A.-S. et al. (2018). Stigma and its association with glycemic control and hypoglycemia in adolescents and young adults with type 1 diabetes: Cross-sectional study, Journal of Medical Internet Research, 20 (4), p. 151.

3. McCarthy, G. (2018). Dear my very problematic blood glucose meter: adolescents' experiences self-managing type 1 diabetes and their psychosocial user requirements of medical technologies.

4. Pullin, G. (2009). Design Meets Disability. Cambridge, Massachusetts: MIT Press.

5. Rodríguez Ramírez, E. \& Chan, K. (2016). Smart interactions for home healthcare: A semantic shift, International Journal of Arts and Technology, 9 (4).

6. Krippendorff, K. \& Butter, R. (1984). Product Semantics: Exploring the Symbolic Qualities of Form, Innovation, 3 (2), pp. 4-9.

7. Rodríguez Ramírez, E. (2012). Semantics of surprise: Strategies for eliciting surprise through design, in Design and 
semantics of form and movement, Victoria University of Wellington.

8. Braun, V. \& Clarke, V. (2012). Thematic analysis., in APA handbook of research methods in psychology, Vol 2: Research designs: Quantitative, qualitative, neuropsychological, and biological., Washington: American Psychological Association, pp. 57-71.

9. Sanoff, H. (1990). Participatory design: theory \& techniques / Henry Sanoff. Raleigh, N.C.: Henry Sanoff distributor.

10. Simonsen, J. \& Robertson, T. (2013). Routledge international handbook of participatory design. New York: Routledge.

11. Martin, B. \& Hanington, B. (2012). Universal Methods of Design. United States of America: Rockport Publishers.

12. Jacobson, S. (2014). Personalised Assistive Products: Managing Stigma and Expressing the Self, Ph.D., Aalto University School of Arts, Helsinki.

13. Vaes, K. (2014). Product Stigmaticity: Understanding, measuring and managing product-related stigma, Ph.D., Universiteit Antwerpen (Belgium), Belgium.

14. Bispo, R. \& Branco, V. (2011). Designing out stigma : a new approach to designing for human diversity.

15. Boeldt, D.L. et al. (2015). How Consumers and Physicians View New Medical Technology: Comparative Survey, Journal of Medical Internet Research, 17 (9), p. e215. 